\title{
SECAGEM NATURAL DE GRÃOS DE DUAS VARIEDADES DE CAFÉ ARÁBICA: REFLEXOS NA CONDUTIVIDADE ELÉTRICA
}

SEGATO, Silvelena Vanzolini ${ }^{1}$

CINTRA, Kauê Pereira ${ }^{2}$

Recebido em: 2020.07.08Aprovado em: 2021.03.11 ISSUE DOI: 10.3738/1982.2278.3819

\begin{abstract}
RESUMO: Na secagem de grãos, as membranas celulares sofrem um processo de desorganização estrutural, assim quanto menor for o teor de água no grão de café, mais desorganizada estará a membrana plasmática. Como existe relação entre a degeneração das membranas celulares e a deterioração do grão de café, procurou-se verificar o comportamento da condutividade elétrica (CE), de duas variedades de café arábica, na colheita e após o processo de secagem natural. Para tanto, duas amostras de café: uma da variedade "Mundo Novo" e outra da "Catuaí" tiveram seus grãos colhidos e avaliados quanto à umidade, à massa e à CE medida, após 5 horas, na solução de embebição de grãos de café. Após tais determinações, as duas amostras foram submetidas à secagem natural dos seus grãos e as avaliações foram refeitas. Conclui-se que na colheita as duas variedades apresentavam valores semelhantes de CE e que a secagem natural aumentou a CE. Contudo, a variedade "Mundo Novo" apresentou menor CE em relação à variedade "Catuaí".
\end{abstract}

Palavras-Chave: Degeneração de membrana celular. Qualidade.Tamanho.Umidade.

\section{NATURAL DRYING OF TWO VARIETIES OF ARABIC COFFEE: REFLECTIONS ON THE ELECTRICAL CONDUCTIVITY}

SUMMARY: In the drying of coffee beans, the cell membranes under go a process of structural disorganization, being more disorganized the lower the water content in the grain, as there is a relation between the degeneration of the cell membranes and deterioration of the coffee bean, it was verified the behavior of the electrical conductivity (EC) of two varieties of Arabica coffee in the harvestand after the drying process of natural drying. In order to do so, two samples of coffee: one from the Mundo Novo variety and another from Catuaí had their grains harvestedand evaluated for moisture, mass and EC measured after 5 hours in the coffee bean imbibition solution. After these determinations, the two samples were submitted to the natural drying of their grains and again the same evaluations were redone. It was concluded that at harvest the two varieties presented similar EC values and that natural drying increased EC in the two coffee varieties. However, the 'Mundo Novo' variety presented lower EC in relation to the Catuaí variety.

Keywords: Cell membrane degeneration. Quality. Size. Moisture.

\section{INTRODUÇÃO}

O café pertence à família Rubiaceae, gênero Coffea, no qual já se encontram descritas mais de 90 espécies. Destas, cerca de 25 são exploradas comercialmente, sendo que apenas quatro têm importância significativa no mercado mundial: Coffea arabica, conhecido como café arábica; Coffea canephora, conhecido como café robusta, e em menor volume: Coffe alibericae Coffea dewevrei, que produzem o café libérica e o café excelsa, respectivamente. Contudo, o café

1 Docente Faculdade Dr. Francisco Maeda- FAFRAM. Fundação Educacional de Ituverava. 
$\overline{\text { arábica (C. arabica L.) é a espécie mais importante do gênero Coffea e responde por cerca de }}$ $70 \%$ do café comercializado mundialmente (SOUZA et al., 2004).

O café arábica representa cerca de $75 \%$ da produção total (arábica e conilon) de café no Brasil. Nos últimos anos a área de café no país vem apresentando redução e esse comportamento tem sido compensado pelo ganho de produtividade alcançado pelos produtores, com a aplicação de novas tecnologias nessa cultura. $\mathrm{Na}$ safra de 2020 é possível, no entanto, perceber leve retomada no crescimento da área total nos principais estados produtores de café, como Minas Gerais, Espírito Santo, São Paulo e Bahia (CONAB, 2020).

Para o café, a qualidade está diretamente relacionada à sua bebida. A presença de grãos imaturos e de grãos pretos devidos às práticas de colheita, secagem e processamento alteram significativamente a composição química dos grãos de café e consequentemente a qualidade de bebida (MAZZAFERA, 1999).

Segundo Borém (2004) para se obter cafés com boa qualidade, vários fatores são importantes, tais como: composição química do grão, determinada por fatores genéticos e ambientais; o processamento e conservação do grão, no qual intervém a ação do teor de água e da temperatura, evitando infecções microbianas indesejáveis; a torração e o preparo da infusão, que modificam a constituição química do grão e que resultam no sabor e aroma percebidos no momento de degustação (ALPIZAR; BERTRAND, 2004; LELOUP et al., 2004; CHAGAS; MALTA; PEREIRA, 2005; FARAH et al., 2006; BORÉM, 2008).

Assim, os compostos químicos nos grãos de café são reflexos de uma série de atributos que, somados, conferem ao café sabor e aromas peculiares. Entre eles, podem-se destacar características edafoclimáticas, fatores genéticos (cultivares), condução e manejo na produção da lavoura, colheita e processamento pós-colheita, tais como: tipo de processamento, secagem e armazenamento (CARVALHO; CHALFOUN, 1985; CARVALHO et al., 1994; MALTA et al., 2003).

Após o processamento do café, a etapa de secagem passa a ser importante tanto sob aspecto de consumo de energia como na influência que essa operação tem sobre a qualidade final do produto. Durante a secagem, os teores de água dos grãos são reduzidos de $60 \%$ para 11,5 \% (b.u), eliminando-se, assim, riscos com respiração, oxidação, fermentações e desenvolvimento de fungos e bactérias (WINTGENS, 2004). Por outro lado, se não forem utilizadas as melhores técnicas de secagem, a qualidade poderá ser prejudicada em decorrência de alterações físicas, químicas e sensoriais indesejáveis (BORÉM et al., 2008b).

Existem dois métodos de processamento para o café: a via seca e a via úmida. No processamento via seca os frutos são submetidos à secagem intactos, sem a remoção do exocarpo. 
No processamento via úmida podem ser produzidos: os cafés cereja descascado, resultados da remoção mecânica da casca e, parcialmente, da mucilagem do fruto; os cafés cereja despolpados, originados de frutos descascados mecanicamente com a mucilagem remanescente removida por fermentação; e os cafés cereja desmucilados, resultado da remoção mecânica tanto da casca quanto da mucilagem (BORÉM et al., 2008a).

A secagem do café é tradicionalmente realizada em terreiros, usando a energia solar e o movimento natural do ar para a remoção da água ou em secadores mecânicos que usam ar forçado aquecido a diferentes temperaturas. No entanto, frequentemente aplica-se a combinação desses dois tipos de secagem, utilizando-se período de pré-secagem em terreiros, quando o café ainda possui elevado teor de água, e a complementação da secagem em secadores mecânicos, com temperaturas elevadas (SAATH, 2006; BORÉM et al., 2008a; TAVEIRA, 2009).

A temperatura do ar de secagem é o parâmetro de maior flexibilidade num sistema de secagem em altas temperaturas influenciando significativamente a taxa e a eficiência de secagem, bem como a qualidade final do produto e, se não for controlada, provoca danos físicos, como descoloração dos grãos, quebras e trincas (OCTAVIANI, 2000; AFONSO JÚNIOR, 2001; RIBEIRO, 2003).Temperaturas mais elevadas diminuem o tempo de secagem, diminuindo custos. Porém, diversas pesquisas têm demonstrado que temperaturas na massa de café, acima de $40{ }^{\circ} \mathrm{C}$ causam prejuízos à qualidade do café (BORÉM et al., 2006; SAATH, 2010; TAVEIRA, 2009).Logo, com a secagem da semente, as membranas celulares sofrem um processo de desorganização estrutural, estando tanto mais desorganizadas quanto menor for o teor de água na semente (BEWLEY, 1986). Existe uma relação entre a degeneração das membranas citoplasmáticas, subsequente perda de controle de permeabilidade, com a deterioração do grão de café (PRETE, 1992).

Neste sentido, a medida de condutividade elétrica é um teste de vigor para avaliar a qualidade fisiológica de sementes e baseia-se no princípio de que com o processo de deterioração ocorre a lixiviação dos constituintes celulares das sementes embebidas em água devido à perda da integridade dos sistemas celulares. Assim, baixa condutividade significa alta qualidade da semente e alta condutividade, indicativo da maior saída de lixiviados da semente, sugere a menor qualidade desta (VIEIRA; KRZYZANOWSKI, 1999).

A secagem do café, se mal conduzida, pode intensificar a degradação de membranas celulares, o que pode ser indicada com consistência pelo teste de condutividade elétrica (AMORIM, 1978; PRETE, 1992). O teste de condutividade elétrica indica possíveis danos ao sistema de membranas celular (AMORIM, 1978; PRETE, 1992). Os grãos com membranas mal estruturadas, desorganizadas e danificadas, lixiviam maior quantidades de solutos, apresentando 
maiores valores de condutividade elétrica (KRZYZANOWSKY; FRANÇA NETO; HENNING. 1991) indicando perda de qualidade (PRETE, 1992; PIMENTA; COSTA; CHAGAS, 2000).

Borém, Marques e Alves (2008) e Marques et al. (2008) mostraram maiores danos no sistema de membranas celulares dos grãos com o aumento da temperatura da secagem. O teste de condutividade elétrica têm se apresentado como indicadores consistentes da integridade de membranas celulares apresentando bebidas de pior qualidade (dura, riada e rio) e os maiores valores de condutividade elétrica têm se apresentado em grãos de café secados sob temperaturas mais elevadas (REINATO, 2003; RIBEIRO, 2003).

Trabalhos relatam danos causados pela secagem em grãos de café, comprometendo a obtenção de uma bebida de boa qualidade. Supõe-se que isso seja devido à desorganização e a desestruturação das membranas celulares, que permitem o contato de componentes químicos com as enzimas hidrolíticas e oxidativas, as quais estão relacionadas aos processos fermentativos, comprometendo o sabor e aroma da bebida (SAATH, 2006).

Goulart et al. (2007) correlacionaram as fotomicrografias de cortes do endosperma de grãos de café classificados como bebida Mole, Dura e Rio com a condutividade elétrica e confirmaram que os grãos que produzem bebida classificada como de pior qualidade apresentam maior condutividade e menor estruturação e organização celular. Estes autores concluem que a condutividade elétrica pode ser relacionada à qualidade das bebidas de café. Duarte (2017) relatou que o teste de condutividade elétrica em grãos de café (classificados em mesma classe de tamanho) está relacionado à qualidade da bebida. Enquanto Borém et al. (2008b) relataram que a condutividade elétrica aumenta com a elevação da temperatura de secagem independente do tipo de processamento.

Como cafés de qualidade superior remuneram mais adequadamente o produtor é ainda mais relevante, neste cenário de preços achatados e custos elevados, a busca por tecnologias que identifiquem, ao longo das etapas de pré e pós-colheita do café, o que pode contribuir positiva ou negativamente com a qualidade final da bebida, e, assim adequar os processos na busca pelo melhor café, nesse sentido a mensuração da condutividade elétrica pode ser uma ferramenta a ser utilizada.

Com base no exposto, o objetivo do trabalho foi verificar a variação da condutividade elétrica de duas variedades de café Arábica no momento da colheita e após o processo de secagem. 


\section{MATERIAL E MÉTODO}

O trabalho teve início em cafezal localizado no município de Claraval, MG (20²0`40”S $\left.47^{\circ} 12^{\prime} 55^{\prime \prime} \mathrm{W}\right)$, com altitude de $968 \mathrm{~m}$.

Foi coletada a mão duas amostras de quatro quilos de café arábica, uma sendo grãos de Catuaí Vermelho e outra Mundo Novo, relacionadas à safra 2018\2019, tais grãos encontravamse em estádio predominantemente passa.

Segundo Souza et al. (2004) a variedade 'Mundo Novo' originou-se do cruzamento natural entre as variedades 'Sumatra' e 'Bourbon Vermelho'. Possui boa adaptação às regiões altas, apresenta elevada rusticidade, vigor e produtividade. É susceptível à ferrugem-do-cafeeiro e apresenta maturação mais precoce e uniforme, com linhagens de 'Mundo Novo' que produzem frutos maiores que os da variedade 'Catuaí'.

A variedade Catuaí é resultante do cruzamento artificial de cafeeiros selecionados de 'Caturra Amarelo', de porte baixo, e 'Mundo Novo'. A planta é bastante rústica e produtiva. A maturação é mais tardia e mais desuniforme do que a variedade 'Mundo Novo'. Apresenta maior susceptibilidade à ferrugem do cafeeiro e a planta fica mais depauperada após alta produção e quando sofre efeito de estresse hídrico ou de deficiência nutricional (SOUZA et al., 2004).

Os grãos dos cafés foram transportados no mesmo dia da colheita, em sacos plásticos fechados, ao Laboratório de Análise de Sementes (LAS), da Faculdade "Dr. Francisco Maeda" FAFRAM, em Ituverava/SP, onde se procederam as avaliações descritas a seguir.

Depois de feita as primeiras avaliações, as amostras das duas variedades foram transportadas novamente até o sítio (Claraval, MG), e, em um terreiro de cimento, foi praticada a secagem natural. Os grãos foram revolvidos a cada 1 hora, permanecendo no terreiro por três dias para finalizar o processo de secagem.

Esses grãos de cada amostra foram colocados em sacos de plástico e retornaram ao Laboratório de Análise de Sementes (LAS) da Faculdade "Dr. Francisco Maeda" - FAFRAM, em Ituverava/SP, para novamente serem avaliados.

As duas variedades de café arábica e as duas etapas (colheita e secagem) serviram de tratamento.

Foi calculado o teor de água dos grãos de cada variedade após a colheita e após a secagem, empregando-se o método da estufa a $105^{\circ} \mathrm{C}$ por 24 horas, segundo as Regras para Análise de Sementes-RAS (BRASIL, 2009). Utilizaram-se três repetições de 50 grãos. Os resultados foram expressos em porcentagem (base úmida). 
Para as duas variedades, após a colheita e a secagem dos grãos, foram feitas determinações da massa úmida em quatro repetições de 50 grãos que foram pesados em balança de precisão de duas casas decimais.

O teste de condutividade elétrica teve como base o procedimento descrito por Malta, Pereira, Chagas (2005). Para cada variedade, quatro amostras de 50 grãos foram pesadas e imersas em $75 \mathrm{~mL}$ de água deionizada (em copos plásticos de $180 \mathrm{~mL}$ de capacidade previamente

identificados) e colocadas em germinador a $25^{\circ} \mathrm{C}$ para o processo de embebição por 5 horas, quando se realizou a leitura da condutividade elétrica, mediante suave agitação da solução de embebição, em condutivímetro de bancada da marca Digimed. Os resultados foram expressos em $\mu \mathrm{S} . \mathrm{cm}^{-1} \cdot \mathrm{g}^{-1}$. A condutividade elétrica foi avaliada após a colheita e após a secagem.

Foi utilizado o delineamento experimental inteiramente casualizado (DIC), executado em esquema fatorial 2 × 2 ( 2 variedades de café x 2 etapas de condução). Os resultados foram submetidos à análise de variância e as médias foram comparadas pelo teste de Tukey a 5\% de probabilidade. O programa adotado para análise dos dados foi o ESTAT.

\section{RESULTADO E DISCUSSÃO}

Houve interação entre variedades e etapas do processamento do café. Assim, a variedade Mundo Novo apresentou maior massa tanto na colheita, quanto após secagem, em relação à variedade Catuaí (Tabela 1).

Tal resultado era esperado, pois "Mundo Novo" possui grãos de maior tamanho e é mais precoce que a variedade Catuaí, segundo Souza et al. (2004).

Tabela 1. Dados médios de massa de 50 grãos (g) de grãos de café de duas variedades nas etapas da colheita e da secagem. Ituverava, SP. 2019.

\begin{tabular}{|c|c|c|c|}
\hline \multirow[b]{2}{*}{ Variedade } & \multicolumn{3}{|c|}{ Massa de 50 grãos (g) } \\
\hline & Colheita & Secagem & Média das variedades \\
\hline Mundo Novo & 6,6 a A & 6,5 a $A$ & $6,57(\mathrm{~A})$ \\
\hline Catuaí & 5,5 a B & $4,5 \mathrm{~b} \mathrm{~B}$ & 4,99 (B) \\
\hline Média das etapas & $6,1(\mathrm{a})$ & $5,5(b)$ & \\
\hline C.V. (\%) & \multicolumn{2}{|c|}{5,17} & \\
\hline
\end{tabular}


A variedade Mundo Novo manteve, estatisticamente, o mesmo valor de massa (Tabela 1), mesmo após a secagem, enquanto a variedade Catuaí apresentou menor massa após secagem. Isso pode indicar maior maturidade dos grãos na variedade Mundo Novo e/ou que o processo de secagem foi mais drástico para a variedade Catuaí.

Para umidade (Tabela 2), também houve interação entre os fatores, mas ambas as variedades apresentaram redução no teor de água após secagem, como era previsto. Contudo, vale destacar que os grãos de café foram colhidos já bem secos e a secagem foi muito drástica, pois levaram esses grãos de café para umidades inferiores as que normalmente são ideais para o armazenamento do café. Segundo Mesquita et al. (2016) a umidade final tem grande importância para a manutenção da qualidade do café, enquanto armazenado, no beneficiamento e para a comercialização. Recomenda-se que umidade final dos grãos fique entre 10,5 a 11,5\%. Essa secagem demasiada pode ter ocorrido, em função do tamanho pequeno da amostra que foi submetida à secagem natural e mesmo tomando cuidados adequados na condução da secagem, provavelmente pela elevação rápida da temperatura, que promoveu secagem rápida da amostra.

Esse aspecto é relevante, pois se não forem utilizadas as melhores técnicas de secagem, a qualidade da bebida de café poderá ser prejudicada em decorrência de alterações físicas, químicas e sensoriais indesejáveis (BORÉM et al., 2008b). Borém, Marques e Alves (2008) e Marques et al. (2008) verificaram maiores danos no sistema de membranas celulares dos grãos de café com o aumento da temperatura de secagem o que pode ter ocorrido no experimento.

Tabela 2. Dados médios de umidade (\%) de grãos de café de duas variedades nas etapas da colheita e da secagem. Ituverava, SP. 2019.

\section{Umidade (\%)}

\begin{tabular}{lllc} 
Variedade & Colheita & Secagem & Média das variedades \\
\hline Mundo Novo & 18,5 a B & $6,8 \mathrm{~b} \mathrm{~A}$ & $12,67(\mathrm{~A})$ \\
Catuaí & 19,9 a A & $5,5 \mathrm{~b} \mathrm{~B}$ & $12,68(\mathrm{~A})$
\end{tabular}

\begin{tabular}{lcc}
\hline Média das etapas & $19,2(\mathrm{a})$ & $6,1(\mathrm{~b})$ \\
\hline C.V. (\%) & 1,93
\end{tabular}

* Médias seguidas de letra distinta diferem entre si pelo teste de Tukey $(\mathrm{P}<0,05)$. Coeficiente de variação $\left(\mathrm{C} . \mathrm{V} . \mathrm{-}^{\mathrm{\%}}\right.$ ) Letras maiúsculas comparam colunas (variedades) e minúsculas linhas (etapas). ( ) indica que houve interação entre variedades $\mathrm{x}$ etapas.

Fonte: Elaborado pelos autores (2020)

$\mathrm{Na}$ colheita, a variedade Catuai apresentava maior umidade (Tabela 2), demonstrando provável menor grau de maturação que a variedade Mundo Novo. 
Contudo, após secagem a variedade Catuaí apresentou menor grau de umidade que a variedade Mundo Novo (Tabela 2), tal fato pode confirmar a menor maturação dessa variedade. A menor umidade pode ser em função da menor massa (Tabela 1) e uma maior área de superfície em relação ao tamanho, ocorrendo maior perda de água em relação à variedade 'Mundo Novo' e segundo Taveira (2009) quanto menor o teor de água do café o aumento da temperatura de secagem leva a efeito negativo na qualidade final.

Novamente houve interação entre os fatores. Como era previsto, a condutividade elétrica (CE) aumentou após a secagem dos grãos nas duas variedades (Tabela 3). Enquanto na colheita, a $\mathrm{CE}$ das duas variedades eram equivalentes. Após a secagem a variedade Catuaí apresentou CE superior à 'Mundo Novo'. Como já relatado por Bewley (1986) com a secagem, as membranas celulares sofrem um processo de desorganização estrutural, estando tanto mais desorganizadas quanto menor for o teor de água na semente. Neste trabalho os grãos do café 'Catuaí' atingiram menores níveis de umidade, e, é sabido que há uma relação entre a degeneração das membranas celulares, subsequente perda de controle de permeabilidade, com deterioração do grão de café (PRETE, 1992).

A maior CE apresentada pela variedade Catuaí denota que as membranas ficaram mais danificadas, pois permitiram maior exsudação de lixiviados dos grãos para a água de embebição (Tabela 3). Esses resultados elevados de CE foram obtidos em função do menor teor de água dos grãos do Catuaí após a secagem e/ou grãos menores, ambos fatores que sabidamente elevam a CE, segundo Loeffler; Tekrony; Egli (1988) e Prete (1992), respectivamente.

Tabela 3. Dados médios de condutividade elétrica $\left(\mathrm{CE}-\mu \mathrm{S} \cdot \mathrm{cm}^{-1} \cdot \mathrm{g}^{-1}\right)$ após 5 horas de embebição dos grãos de café de duas variedades nas etapas da colheita e da secagem. Ituverava, SP. 2019.

\section{$\mathrm{CE}\left(\mu \mathrm{S} \mathrm{cm} \mathrm{cm}^{-1} \mathrm{~g}^{-1}\right)$}

Variedade Colheita Secagem Média das variedades

\begin{tabular}{lrrr}
\hline Mundo Novo & $63,52 \mathrm{~b} \mathrm{~A}$ & 99,24 a B & $81,38(\mathrm{~B})$ \\
Catuaí & $67,86 \mathrm{~b} \mathrm{~A}$ & 170,09 a A & $118,98(\mathrm{~A})$ \\
\hline
\end{tabular}

\begin{tabular}{lcc}
\hline Média das etapas & $65,69(\mathrm{~b})$ & $134,67(\mathrm{a})$ \\
\hline C.V. (\%) & \multicolumn{3}{c}{11,33}
\end{tabular}

* Médias seguidas de letra distinta diferem entre si pelo teste de Tukey $(\mathrm{P}<0,05)$. Coeficiente de variação (C.V.-\%). Letras maiúsculas comparam colunas (variedades) e minúsculas linhas (etapas). ( ) indica que houve interação entre variedades $\mathrm{x}$ etapas.

Fonte: Elaborado pelos autores (2020)

Contudo, fica evidente que a secagem deve ser bem conduzida para manter a qualidade do grão de café, se mal conduzida, pode intensificar a degradação de membranas celulares, podendo 
ser indicada com consistência pelo teste de condutividade elétrica (AMORIM, 1978; PRETE, 1992).

A maior CE da 'Catuaí' após a secagem poderia resultar em menor qualidade de bebida, pois segundo Goulart et al. (2007) os grãos que produzem bebida classificada como de pior qualidade apresentam maior condutividade e menor estruturação e organização celular. Reinato (2003); Ribeiro (2003); Goulart et al. (2007) e Duarte (2017) concluem que a condutividade elétrica pode ser relacionada à qualidade das bebidas de café.

Com base nos resultados expostos neste trabalho (Tabela 1, 2 e 3), verificou-se que houve diferença de comportamento entre as variedades avaliadas e esse fato pode influenciar a qualidade final do café como relatado na literatura (CARVALHO; CHALFOUN, 1985; CARVALHO et al., 1994; MALTA et al., 2003; BORÉM, 2004). Antes da secagem dos grãos de café (na colheita) as duas variedades apresentavam valores semelhantes de condutividade elétrica (CE). A secagem levou ao aumento da CE nas duas variedades de café. Em função do menor tamanho dos grãos da variedade 'Catuaí', a secagem foi mais drástica (resultando em menor umidade nos grãos) do que na 'Mundo Novo'. Assim, após a secagem natural, a CE foi maior na variedade 'Catuaí' que na 'Mundo Novo', refletindo a maior desestruturação das suas membranas celulares o que poderia, segundo a literatura consultada (PRETE, 1992; REINATO, 2003; RIBEIRO, 2003; SAATH, 2006; GOULART et al., 2007; DUARTE, 2017), levar a uma menor qualidade da bebida.

\section{CONCLUSÃO}

Com base nos resultados expostos neste trabalho conclui-se que na colheita as duas variedades de café Arábica apresentavam valores semelhantes de condutividade elétrica (CE) e que a secagem natural levou ao aumento da CE, nas variedades Mundo Novo e Catuaí. Contudo, a 'Mundo Novo' apresentou menor valor de CE em relação à variedade 'Catuaí' após a secagem natural.

\section{REFERÊNCIAS}

AFONSO JÚNIOR, P. C. Aspectos físicos, fisiológicos e da qualidade do café em função da secagem e do armazenamento. 2001. 373 f. Tese (Doutorado em Engenharia Agrícola) Universidade Federal deViçosa,Viçosa, 2001.

ALPIZAR, E.; BERTRAND, B. Incident of elevation on chemical composition and beverage quality of coffee in Central America. In: INTERNATIONAL CONFERENCE I COFFEE SCIENCE, 20.,2004, Bangladore. Resumes... Bangladore: ASIC, 2004. 1 CD-ROM 
AMORIM, H. V. Aspectos bioquímicos e histoquímicos do grão de café verde relacionados com deterioração da qualidade. 1978. 85 f. Tese (Livre Docência em Bioquímica) - Escola Superior de Agricultura “Luiz de Queiroz”, Piracicaba, 1978.

BEWLEY, J. D. Membrane changes in seeds as related to germination and the perturbations resulting from deterioration in storage. In: McDONALD JR., M. B.; NELSON, C. J. (Eds.) Physiology of seed deterioration. Madison: CSSA, 1986. p.27-45.

BORÉM, F. M. Cafeicultura empresarial: produtividade e qualidade. Lavras: UFLA/FAEPE, 2004. 103 p.

BORÉM, F. M. Processamento do café. In: BORÉM, F. M. Pós-colheita do café. Lavras: Editora da UFLA, 2008. p. 127-158.

BORÉM, F. M.; MARQUES, E. R.; ALVES, E. Ultra stuctural analysis damage in parchment Arabica coffee endosperm cells. Biosystems engineering, Saint Joseph, v. 99, n. 1, p. 62-66, jan. 2008.

BORÉM, F. M. et al. Qualidade do café submetido a diferentes temperaturas, fluxos de ar e períodos de pré-secagem. Coffee Science, Lavras, v. 1, n. 1, p. 55- 63, abr./jun. 2006.

BORÉM, F. M. et al. Caractization of the moment of endosperm cell damage during coffee drying. In: INTERNATIONAL CONFERENCE ON COFFEE SCIENCE, 22, 2008, Campinas. Resumes... Campinas: ASIC, 2008a. p. 14-19.

BORÉM, F. M. et al. Qualidade do café na qualidade do café natural e despolpado após secagem em terreiro e com altas temperaturas. Ciênc. agrotec., Lavras, v. 32, n. 5, p. 1609-1615, set./out., 2008 b.

BRASIL. Ministério da Agricultura. Regras para análise de sementes. Brasília: 1992. 365p

CARVALHO, V. D. de; CHAGAS, S. J. R.; CHALFOUN, S. M.; BORTREL, N.; JUSTE JÚNIOR, E. S. G. Relação entre a composição físico-química dos grãos de café beneficiado e a qualidade da bebida do café. Pesquisa Agropecuária Brasileira, Brasília, v. 29, n. 3, p. 449-445, mar. 1994.

CARVALHO, V. D.; CHALFOUN, S. M. Aspectos qualitativos do café. Informe Agropecuário, Belo Horizonte, v. 11, n. 126, p. 79-92, 1985.

CHAGAS, S. J. R. de; MALTA, M. R.; PEREIRA, R. G. F. A. Potencial da região Sul de Minas Gerais para produções de cafés especiais: I., atividade da polifenoloxidade, condutividade elétrica e lixiviação de potássio. Ciência e Agrotecnologia, Lavras, v. 29, n. 3, p. 590-597, maio/jun. 2005.

CONAB. Companhia Nacional de Abastecimento. Acomp. safra brasileira de café, v. 6- Safra 2020, n. 1- Primeiro levantamento, Brasília, p. 1-62, janeiro 2020. Disponível em: https://www.conab.gov.br/info-agro/safras/cafe. Acesso em: 07 jul. 2020.

DUARTE, M.N. Qualidade da bebida de café baseada na classificação "Specialty Coffee Association of America" e na condutividade elétrica. 2017. 34f. Graduação. (Agronomia) Faculdade Dr. Francisco Maeda, Ituverava. 2017. 
FARAH, A. et al. Correlation between cup quality and chemical atributes of brazilian coffee. Food Chemistry, Oxford, v.98, n. 2, p. 373-380, Feb. 2006.

GOULART, P.F.P.et al. Aspectos histoquímicos e morfológicos de grãos de café de diferentes qualidades. Ciência Rural, v.37, n.3, p. 662-666, 2007.

KRZYZANOWSKY, F. C.; FRANÇA NETO, J. B.; HENNING, A. A. Relatos dos testes de vigor disponíveis as grandes culturas. Informativo ABRANTES, Brasília, v. 1, n. 2, p. 15-50, mar. 1991.

LELOUP, V. et al. Impact of wet and dry process on green coffee composition and sensory characteristics. In: INTERNATIONAL CONFERENCE IN COFFEE SCIENCE, 20., 2004, Bangladore. Resumes... Blangladore : ASIC, 2004. 1 CD_ROM.

LOEFFLER, L.M.; TEKRONY, D.M.; EGLI, D.B. The bulk conductivity test as na indicator of soybean seed quality. Journal of Seed Technology, v.12, n.1, p.37-53, 1988.

MALTA, M. R.et al. Composição química, produção e qualidade do café fertilizado com diferentes fontes e doses de nitrogênio. Revista Ciência e Tecnologia, Lavras, v. 27, n. 6, p. 1246-1252, dez. 2003.

MALTA, M. R.; PEREIRA, R. G. F. A.; CHAGAS, S. J. de R. Condutividade elétrica e lixiviação de potássio do exsudato de grãos de café: alguns fatores que podem influenciar essas avaliações. Ciência e Agrotecnologia, Lavras, v. 29, n. 5 p. 1015-1020, set./out. 2005.

MARQUES, E. R. Alterações químicas, sensoriais e microscópicas do café cereja descascado em função da taxa de remoção de água. 2006. 85f. Dissertação (mestrado em ciência dos alimentos) - Universidade federal de Lavras,Lavra, 2006.

MARQUES, E. R.et al. Eficácia do teste de acidez graxa na avaliação da qualidade do café arábica (Coffea arábica L.), submetidos a diferentes períodos de temperatura e pré- secagem.

Ciência e Agrotecnologia, Lavras, v. 32, n. 5, p. 1557-1562, set/out. 2008.

MAZZAFERA, P. Chemical composition of defective coffee beans.Food Chemistry, v. 64,.p. 547-554. 1999.

MESQUITA, C.M. et al. Manual do café: colheita e preparo (Coffea arábica L.). Belo Horizonte: EMATER-MG, 2016. 52 p.

OCTAVIANI, J. C. Secagem de café cereja descascado desmucilado com utilização de gás liquefeito de petróleo. 2000. 101 f. Dissertação (Mestrado em Engenharia Agrícola) Universidade Estadual de Campinas, Campinas, 2000.

OLIVEIRA, P. D. Aspectos ultra estruturais e fisiológicos associados a qualidade da bebida de café arábica submetido a diferentes métodos de processamento e secagem/ Pedro Damasceno de Oliveira. - Lavras: UFLA, 2010.

PIMENTA, C. J.; COSTA, L.; CHAGAS, S. J. R. Peso, acidez, sólidos solúveis, açúcares e compostos fenólicos em café (Coffea arábica L.), colhidos em diferentes estágios de maturação. Revista Brasileira de Armazenamento, Viçosa, MG, n. 1, p. 23-30, 2000. Especial Café.

PRETE, C. E. C. Condutividade elétrica do exsudato de grãos de café (Coffeaarabica L.) e sua relação com a qualidade de bebida. 1992. 125 f. Tese (Doutorado em Fitotecnia) - Escola superior de agricultura “Luiz de Queiroz", Piracicaba, 1992. 
REINATO, C. H. R. Avaliação técnica, econômica e qualitativa do uso de lenha e GLP na secagem de café. Revista Brasileira de Armazenamento, Viçosa, n. 7, p. 3- 13, 2003. Edição especial.

REINATO, C. H. R.et al. Influência da secagem, em diferentes tipos de terreiro, sobre a qualidade do café ao longo do armazenamento. Coffee Science, Lavras, v. 2, n. 1, p. 48-60, jan/ jun. 2007.

RIBEIRO, D. M. Qualidade do café cereja descascado submetido a diferentes temperaturas, fluxos de ar e períodos de pré-secagem. 2003. 86 f. Dissertação (Mestrado em Ciências dos Alimentos) Universidade Federal de Lavras, Lavras, 2003.

SAATH, R. Microscopia eletrônica de varredura do endosperma de café (Coffea arábica L.) durante o processo de secagem. 2006. 90 f. Dissertação (Mestrado em Engenharia Agrícola) Universidade federal de lavras, Lavras, 2006.

SOUZA, F.F. et al. Características das principais variedades de café cultivadas em

Rondônia. Porto Velho: Embrapa Rondônia, 2004. 21 p. (Documentos / Embrapa Rondônia).

TAVEIRA, J. H. S. Aspectos fisiológicos e bioquímicos associados à qualidade de bebida de café submetido a diferentes métodos de processamento e secagem. $2009.58 \mathrm{f}$. Dissertação (Mestrado em Ciências dos Alimentos) - Universidade Federal de Lavras, Lavras, 2009.

VIEIRA, R.D.; KRZYZANOWSKI, F.C. Teste de condutividade elétrica. In: KRZYZANOWSKI, F.C.; VIEIRA, R.D.; FRANÇA NETO, J.B. (Ed.) Vigor de sementes: conceitos e testes. Londrina: ABRATES, 1999. p.4.1- 4.26

WINTGENS, J. N. Coffee: growing, processing, sustainable prodution. Weinheim: [s.n.], 2004. $711 \mathrm{p}$. 